\title{
Oralidad y subalternidad: La creación de la Tierra y otras Historias del buen Sibú y de los bribris de Adela Ferreto
}

\section{Orality and subalternity: The creation of the Earth and other Stories of the good Sibú and the bribris by Adela Ferreto}

\author{
Abelardo Hernández Gómez ${ }^{1}$
}

Fecha de recepción: 14-06-2019

Fecha de aceptación: 8-06-2020

\begin{abstract}
Resumen
Este trabajo propone una reflexión acerca del papel de una de las manifestaciones indígenas existentes en el territorio costarricense, por ejemplo, la cultura Bribri, dentro de la literatura -alfabética-occidentalizada. El propósito es vislumbrar el lugar de las tradiciones culturales indígenas dentro de la institución literaria. Para tales fines se toma el texto de Adela Ferreto: La creación de la Tierra y otras Historias del buen Sibú y de los bribris, cuya narratividad se fundamenta en la oralidad indígena. Palabras clave: oralidad, literatura, heterogeneidad, subalternidad, indígena.
\end{abstract}

\begin{abstract}
This work proposes a reflection on the role of one of the indigenous manifestations existing in the Costa Rican territory, for example, the Bribri culture, within the westernized (alphabetical) literature. The objective is to highlight the position of indigenous cultural traditions within the literary institution. For such purpose, the text of Adela Ferreto La creación de la Tierra y otras Historias del buen Sibú y de los bribris (The creation of the Earth and other Stories of the good Sibú and the bribris), whose narratives are based on indigenous orality, is considered.

Keywords: oral, literature, heterogeneity, subordination, indigenous.
\end{abstract}

1 Máster en Enseñanza del Castellano y Literatura. Departamento de Filosofía, Artes y Letras, Sede de Occidente, Universidad de Costa Rica. Correo electrónico: ahernand@so.ucr.ac.cr 


\section{Introducción}

En los finales de los 70 Antonio Cornejo ${ }^{2}$ ya planteaba la tarea de repensar acerca de la necesidad de adecuar el ejercicio crítico a las particularidades de la literatura latinoamericana. Este teórico peruano propuso que se trata de demostrar cierta posibilidad de observar cómo se legitima el tratamiento crítico a la literatura con un doble estatuto sociocultural. En este sentido, reconoce Cornejo el aporte de Mariátegui ${ }^{3}$ al intentar construir un sistema analítico capaz de dar explicación de tales literaturas.

Para Cornejo las historias literarias suelen privilegiar el concepto de "nación", asunto que en algunas ocasiones se trata superficialmente, además de estar sometido a las conflictivas relaciones entre lo nacional y lo cultural.

En el ámbito de la literatura costarricense, la cuestión también se puede pensar de manera similar, pues el concepto de literatura nacional está presionado por la fuerza de categorías mayores, regionales o subregionales. No obstante, el concepto de literatura nacional se discute en tanto se trata de la urgencia por recurrir a categorías más explicativas sobre esta.

En ese sentido, apunta Cornejo (1978) que se pueden encontrar los planteamientos marxistas acerca de la coexistencia de una cultura explotada y otra explotadora, coexistencia que divide de lado a lado el campo de la literatura nacional.

Las literaturas deben pensarse en términos complejos, ya que el análisis de un proceso literario permite caracterizar su producción, referentes y consumo, entre otros aspectos, los cuales anuncian diversos grados de heterogeneidad. Este tipo de perspectiva permite establecer cierta distancia entre los textos, por lo cual también surgen variaciones críticas para su tratamiento.

Según Cornejo (1978), una movilización de todas las instancias del proceso literario dentro de un mismo espacio sociocultural determina el surgimiento de lo que se considera literaturas homogéneas, fenómeno en el cual se inscribe La creación de la Tierra y otras Historias del buen Sibú y de los bribris.

Con respecto al caso aquí en estudio, en relación con la pretendida homogeneidad, se pone en juego la perspectiva de ciertos sectores de clase media urbana costarricense, con militancia política en la izquierda, y se emplean los atributos de la modernidad que caracterizan la acción de ese grupo social-político, lo cual, en concreto, refuerza el sistema técnico de la narración. Se alude así, por referencias a la problemática del mismo estrato, donde son leídos por un público de igual signo social. Esto es, una propuesta literaria legible y en concordancia ideológica con determinado grupo social occidentalizado.

Dichos textos son leídos en un marco contextual en el que se destaca, por ejemplo, ser parte del corpus oficial de lecturas para la educación media costarricense, el reconocimiento de la "autora" como escritora de literatura infantil, y su militancia política como elementos que refuerzan una circulación de los textos en determinado espacio sociocultural. Entonces, la producción literaria transita, particularmente, en un determinado espacio social, y cobra así una mayor cuota de homogeneidad en el sentido que propone Cornejo.

Por otro lado, un determinante de las literaturas heterogéneas es la pluralidad de los signos socioculturales de su proceso constructivo, esto es, un proceso que al menos posee un aspecto no coincidente con los otros y crea obligatoriamente un área de conflicto y ambigüedad. Así, al tomar, por ejemplo, el nivel de conciencia de los personajes del texto literario en análisis surge la cuestión en términos antinómicos: de un lado, un referente - el mundo bribri- que no puede proponer su forma de conciencia como perspectiva hegemónica capaz de componer la obra de forma pertinente, es decir, bajo la visión Bribri; y del otro, dicho mundo se encuentra en un nivel subalterno dentro de la formación social que lo somete y define, y desde donde solo se puede reproducir

2 Cornejo Polar, A. 1978. El indigenismo y las literaturas heterogéneas. Su doble estatuto sociocultural. En Revista de Crítica Literaria Latinoamericana. Año $4 \mathrm{~N}^{\mathrm{o}} 78$, págs 7-21. 
bajo algún tipo de género literario, en este caso el "cuento infantil". De tal manera que el texto de Ferreto se presenta como un tipo de literatura homogénea.

Para Ángel Rama (1974), la heterogeneidad ${ }^{4}$ se produce en los procesos constructivos de las formas literarias, en tanto dichas formas originarias -construidas por la cultura indígena- son la canción y el cuento folklórico, mientras que la cultura dominante propone la novela y el cuento enmarcado en los modelos regionalista-sociales, los que se encuadran dentro del realismo europeo de la segunda mitad del siglo XX.

En tales condiciones es que se identifica la narración de Ferreto La creación de La Tierra y otras Historias del buen Sibú y de los bribris. Se debe inferir que la lucha por la forma, en su primer momento, o sea, en la escogencia genérica, se decide por aspectos que se rigen desde la cultura occidentalizada. Es decir, por una parte, hay un elemento heterogéneo ficticio, la oralidad Bribri, y por otra, un aspecto ficcional, la narración de Ferreto que se impone culturalmente. En dicho sentido, un texto se pasa de lo heterogéneo ficticio a lo homogéneo real. Cabe apuntar que por homogéneo ficticio se entiende la idealización que desde la escritura realiza el autor del mundo Bribri. Dicho juego, de lo heterogéneo a lo homogéneo, se deja observar desde los paratextos de La creación de La Tierra y otras Historias del buen Sibú y de los bribris.

De acuerdo con Genette (1987), el paratexto es fundamentalmente un discurso auxiliar con carácter verbal, cuya intención es asegurar la legibilidad del libro, es decir, está en función del texto. En este sentido, se encuentra precediendo el libro de Ferreto un "prólogo" titulado Los bribris, luego el título -general- del texto, y por último, cada historia o cuento tiene su propio título y resumen. Cabe anotar que en todos ellos hay referentes lingüísticos castellanos que imitan o tratan de hacerlo con respecto a la oralidad Bribri.

\section{Bribris}

La creación de La Tierra y otras Historias del buen Sibú y de los bribris reescribe, parcialmente, la cosmovisión del mundo indígena talamanqueño. El volumen es presentado por un prólogo, Los bribris, cuyo tono épico-pastoril evoca una geografía paradisiaca y cierta epopeya indígena con la que se trata de encubrir el etnocidio cultural, con ello se priva a esta comunidad de su condición de sujeto histórico, y en cambio, privilegia la "necesidad" de cierta unidad sentimental entre los lectores y los proveedores textuales, es decir, los Bribris. Así, se trata de sanar la "herida" cultural provocada por la conquista y colonización eurocéntrica.

Se deja claro en el prólogo de la obra que ese mundo natural en el que vive la comunidad Bribri posee una riqueza natural y económica desconocida y no explotada hasta la fecha. También, con nitidez se afirma que los Bribris están o mantienen determinado nivel de pureza cultural, y todo ello los hace dignos representantes del sustrato cultural identitario costarricense. Ferreto (1985): "Cordillera de Talamanca. Fabulosa cordillera cuyos picos son los más altos de Centro América...recorrida desde los tiempos de la Conquistas por numerosas expediciones, en busca de unas famosas minas de oro, nunca encontradas" (p. 7).

Además, dicho prólogo no deja dudas acerca de las fuentes sobre las "historias", pues estas se inspiran en la obra antropológica de María E. Bozzoli de Willie, y según Ferreto (1985), por la tradición de resistencia cultural del pueblo Bri bri. Esto último con carácter secundario, pues la legitimidad de las fuentes es sustentada por la autoridad académica.

Junto al tachón histórico, es decir, las repercusiones socioculturales que ha causado la represión cultural sobre el pueblo Bribri, cabe la insistencia de la escritora en cuanto al objetivo del texto, preservar algunas de las tradiciones bribris, como algunos de sus valores, pues según la misma Ferreto (1985) “...son nuestra tradición más antigua, más autóctona” (p. 7). Esto es, una promoción simbólica de ciertas reivindicaciones de la autoctonía cultural indoamericana.

4 Véase al respecto: Ángel Rama. 1975. Formación de una cultura nacional. José Mo Arguedas. 6ta ed. Siglo XXI. México. 
En dicho sentido, este paratexto genera condiciones básicas que aclaran el porqué de la inserción del indígena en los campos de la literatura y la significación de tal irrupción. De tal manera, el texto de Ferreto hace necesaria, por una parte, la historicidad del ser costarricense que desde la literatura recupere el aporte del mundo ancestral al moderno, producto del mestizaje. Por otra, y complementariamente, una originalidad ancestral que dote al texto de capacidad de convocatoria para reunir a través suyo dos mundos: el del lector/dominador y el del narrador/dominado, con lo que trata de superar las distancias establecidas por la conquista, aunque en el prólogo supracitado se indica que “...los bribris jamás conquistados por los españoles; ni con la espada del soldado, ni con la cruz del misionero" (p. 7). Es decir, se desprende del texto una reivindicación triunfal del mundo indígena sobre el conquistador al lograr el primero que se transmitan sus valores como modelo de vida sobre el arquetipo occidental.

Con esto la literatura se proyecta como heroína, como aquella que sabe extraer de lo negativo lecciones para mejorar el presente y el futuro: "Ojalá, al leerlas, se sintieran en verdad unidos y hermanados con nuestros pueblos aborígenes, que es lo que debe ser" (Ferreto, 1985, p. 7). No obstante, esta incorporación de la oralidad indígena queda subordinada al orden discursivo escrito. Se trata, desde una perspectiva crítica, de subrayar cómo la cultura letrada se ocupa de la construcción de cierto tipo de oralidad ficticia para alcanzar algunos objetivos, entre ellos, recrearse a sí misma como un ente superior frente a la oralidad.

Ahora bien, este paratexto de Ferreto conduce hacia la asunción de un modo de ser, a una madurez literaria que le facilita presentarse ante un público particular, los niños, o ante una cultura considerada superior, lo cual podría hacer alusión a algunas ideas de la Ilustración acerca del Nuevo Mundo. En este sentido, las leyendas indígenas deben ser consideradas como propias para públicos infantiles, pues se trata, en primera instancia, de preservar los valores de una cultura con siglos de madurez para enriquecer la otra cultura, la nacional, transmitiendo los valores y aspectos básicos de la identidad costarricense de esta primera a personas de corta edad.
Cabe destacar que tanto Adela Ferreto, como Carmen Lyra y María Leal de Noguera, quienes combinaron su profesión de maestras con la creación literaria, estuvieron influenciadas por las ideas pedagógicas que se exponían en la Escuela Normal de Costa Rica de la primera mitad del siglo XX, entre ellas, educar para las transformaciones sociales. En este sentido, su obra literaria se ofrece como vehículo ideal para tales fines. Sin embargo, de acuerdo con Cros (2003), los sujetos son atravesados por una cultura que funciona como memoria colectiva, que por una parte actúa como celadora de la ideología dominante, y por otra, se presenta como una deformación de sí por las acciones y personajes que reproducen los valores del poder. De tal forma que la reproducción escrituraria de Ferreto incluye una falsa oralidad con la idea de exaltar valores de un mundo marginado, negado del que hay registros que llaman la realidad, realidad que desaparece en beneficio de la representación a través de la palabra escrita.

Ahora, cabe resaltar que este texto de Ferreto se publicó en 1985, cuando los proyectos políticos pensados desde la Modernidad ya mostraban contradicciones; dicha narración sugiere que las ideas revolucionarias inspiradas por el Partido Comunista Costarricense (1931) sean respuesta al vacío dejado por el pensamiento de corte socialdemócrata de gran influencia en Costa Rica.

\section{Historias}

Un primer aspecto por considerar es que todos los textos obedecen a un mismo formato tripartito, es decir, hay un título que remite al tema central de la historia o cuento, luego un "texto introductorio" que amplía desde la cosmovisión bribri o pretende hacerlo el contenido de dicho título, y por último, la historia o cuento. De esta forma, tanto los títulos como los textos introductorios propuestos por Ferreto -para cada historia o cuento-, invocan antecedentes acerca de cómo se concibe el mundo al cual pertenecen los sujetos representados, de quienes dan razón por medio de una oralidad inmediata o posible. Es decir, que en las doce historias o cuentos propuestos dichos paratextos contextualizan el espacio socio-cultural y físico en los cuales se produce una interacción social 
que posibilita diálogos entre los personajes, padre e hijo, cuyos temas versan acerca de mitos antropogónicos, cosmogónicos y biocosmogónicos Bribri. Así, registrar y entregar las concepciones acerca del Cosmos o del Universo de las pueblos orales conduce a crear en la cultura letrada condiciones que posibilitan concebir otras culturas como objetos para el disfrute y fuente de enriquecimiento solo en beneficio de lo letrado.

Por otra parte, de acuerdo con Marcone (1997), la inscripción de la oralidad en textos escritos tiene como meta reforzar la idea de la superioridad de la escritura sobre la oralidad, puesto que la oralidad no puede entrar en el texto escrito por cuanto ella no es solo acto de habla, sino evento trascendente e histórico en el que participan variables que se resisten a esa incorporación. Se trata, en opinión de este teórico, que con las transcripciones de la oralidad esta es traicionada, pues al introducir mediaciones ideológicas, tal como lo declara Ferreto (1985), se eliminan aspectos vitales de la oralidad.

Así, esos discursos presentes en el texto literario proponen una diferencia en la construcción imaginaria de la subjetividad desde la voz de una enunciante que narra desde el modelo colonizador:

Juanillo iba subiendo, junto con su papá, Juan grande, una larga cuesta del camino. Gotas de sudor resbalaban por su carita morena y se perdían bajo el cuello de su camisa de manta. Como se sentía cansado ${ }^{5}$ se sentó sobre un tronco de la orilla y puso la carga de leña y ramas; Juan grande hizo lo mismo; ambos se enjugaron el sudor con el dorso de la mano. (p .11)

Con tal de dotar de la mayor credibilidad a su texto, Ferreto autora/narradora aplica un procedimiento sugestivo, pues utiliza el paratexto para ubicar geoculturalmente su "narración" y así convencer al lector de que está "oyendo voces indígenas" encarnadas en personajes y narradores, también indígenas. Para ello, además de españolizar el habla indígena, también lo hace con su contexto al elaborar un doble proceso de ficcionalización, así, finge lo oral en la escritura (utilizando determinados recursos gráficos como guiones y otros para indicar representaciones de la oralidad) y el español como la lengua bribri.

Por esa vía, la escritura se presenta homogénea, aparentando transculturalidad y discontinuidad, inserta en la tradición establecida por la norma letrada, además de que asimila, o lo intenta hacer, las formas lingüísticas orales, quedando estas últimas invisibilizadas.

Luego de tales introducciones aparecen enunciados con carácter de súplica e invocación por parte del niño indígena a su padre y las respuestas de este. Se hace notar cómo la mayor cantidad de las historias se introducen con las fórmulas "Te lo voy a decir...; Te lo voy a contar".

Se trata de una práctica discursiva que simultáneamente se apodera e invisibiliza los elementos orales, dejando percibir cierta vigencia socio-cultural de resistencia. En este sentido, nótese la estructura gramatical utilizada por Ferreto, así como la falta de marcas dialectales. Asimismo, antes de que aparezca propiamente "el diálogo" entre los personajes, hay una intervención de la narradora, como en los siguientes ejemplos: El niño suplicó... (p. 7); Juan grande habló... (p. 21); Así se lo contó Juan al pequeño Juanito... (p. 31). Con estas estructuras gramaticales, la narradora establece relaciones entre las partes del discurso y sus integrantes, y consigue una cohesión que da verosimilitud al texto.

Apunta Mato (1995), en relación con la literatura oral, que esta es un constructo creado para determinar algunas prácticas escriturales de corte popular, cuya difusión se funda en la memoria colectiva. Cabe anotar que esta definición se fundamenta en la palabra escrita y por consiguiente se orienta a negar, desde la óptica de pueblos víctimas del fetichismo del alfabeto, a tales comunidades que por su estadio de evolución no han inventado un código alfabético. En este sentido, el texto de Ferreto evidencia la predilección occidental por la palabra escrita como guardián de sus prácticas semióticas, contrario a los pueblos ancestrales de América.

5 El destacado obedece al interés del investigador, pues la idea del cansancio es reiterada en otros textos ficcionales, de modo que se torna un elemento significativo. 
$\mathrm{Al}$ imponerse con la conquista el alfabetismo europeo en la cima del poder político de América, los sistemas de comunicación propios fueron marginados, subalternados política y socialmente, empezando con los pueblos autóctonos y luego con todos aquellos que no estuvieron en la esfera de la ciudad letrada occidentalizada.

Ahora, ¿cómo abordar la "oralidad" desde la escritura sin perjudicarla? En primer término se debe reconocer su especificidad, concibiéndola como un sistema particular de comunicación, reproducido por una memoria colectiva la cual le garantiza cierta ciclicidad, que se presenta como un conjunto de elementos con carácter expresivo. Esto hace que se oriente hacia la totalidad de los sentidos de la percepción, y no sea una simple particularidad del discurso verbal. En segundo lugar, la oralidad es vivencia real, es decir, los textos orales dependen en mucho de los contextos comunicativos. En este orden, toda trasposición o transcripción de gestualidad, de determinadas inflexiones fonéticas que suponen un modo de procesar mensajes, una sensibilidad y formas de relacionarse con el mundo, es reducida por la literatura, así, por una parte, las prácticas de escritura privan de sus contextos culturales la oralidad, y por otra, los incluye.

La oralidad desde dentro, es decir sin contacto, permite una percepción y evocación (perfomance) de sus protagonistas acerca de su propia práctica, así, sus emisores y destinatarios son miembros de una comunidad establecida en un espacio geográfico, con repertorios formalizados de gestos, sonidos y acciones cotidianas o no. Todo ello en relación estrecha entre sus productores.

La oralidad en situación de contacto, es decir, desde afuera, provoca el empleo (perfomance) de medios, códigos y recursos no orales, como guiones y otros elementos mnemotécnicos, textos escritos u otros de origen alfabético, que se orientan hacia un destinatario fuera o ajeno de la comunidad orante, además de darse en un escenario extraño. Esta es la situación del corpus aquí indagado, empero, en este caso se observa una escasa presencia de esos recursos alfabéticos que visualicen la oralidad en la escritura, en la que incluso se muestran diferencias notables entre el texto de Bozzoli (1979) y el de Ferreto, en estudio.
De tal manera, la relación con el otro se define desde dentro de la cultura dominante; en otras palabras, desde la complejidad de esa constitución que es un espacio heterogéneo como lo refiere Cornejo.

Por otra parte, con respecto a los escritores que obtienen éxito en la reelaboración de las artes orales indígenas, como Adela Ferreto, Magda Zavala (1998) señala que muchas de esas reelaboraciones se producen bajo los parámetros de lo que se denomina "literatura infantil", donde no en pocas ocasiones se cree que existen determinadas relaciones entre el mito indígena y la literatura infantil, teniendo esto relación aun con el espíritu de la Ilustración, que sostuvo que el buen salvaje es como un niño -occidental- y que las culturas indígenas son como la infancia de los pueblos.

Aclarado el punto anterior, Zavala (1998) apunta a que dicho espacio -la literatura infantil- es fecundo para la receptividad del mito indígena, pues con un tratamiento ficcional se torna materia ejemplarizante. Un ejemplo de ello -entre varios ofrecidos por el texto de Ferreto- es la manera en cómo Juanillo (personaje de la primera historia) pide a su padre que le cuente acerca del origen de los Bribris. Tal es el caso también de Surayom, La tierra de nuestro origen, historia en la cual el personaje central, Sibú, busca esposa, y para ello se disfraza de mendigo, tal como señala Ferreto (1985) en el siguiente pasaje: "Sibú, el Todopoderoso, se disfrazó de mendigo: tomó ropas viejas, andrajosas, sucias; con el pelo desgreñado, con las barbas desgreñadas, con el rostro cubierto de mugre...pero no pudo cambiar sus ojos, fue lo único que no pudo cambiar...” (p. 17).

Nótese, por una parte, cómo el disfraz de Sibú es un atuendo totalmente occidentalizado, y se pinta un ser harto conocido en el mundo occidental, el mendigo, lo que permite observar una reelaboración del indígena con carácter eurocéntrico. Por otra parte, dicha reconstrucción se cuestiona más al llevarse a cabo el ritual del lavado en el río, donde Sibú se despoja de tales vestimentas y surge resplandeciente como el sol. Así, este ofrece una lección ejemplarizante a las hermanas de Tsirú acerca de las falsas expectativas que la apariencia facilita, aspecto también occidentalizado que Tsirú rechaza al acceder a casarse con el Todopoderoso Sibú. 
Una vez alcanzado su objetivo, el personaje se somete a un determinado ritual natural, hecho que evidencia, por un lado, el empoderamiento del mundo indígena, y por otro, el rechazo al sometimiento a un mundo cultural distinto. En dicho sentido, cuando un tipo de personajes desarrollan sus actos de acuerdo con "hechos maravillosos”, en este caso de carácter bíblico, y donde estos actos hacen posibles sus deseos, se clasifican como relatos fantásticos, apropiados para niños.

Asimismo, los relatos inician con un resumen de la historia, es decir, se presenta el tema por narrar, y seguidamente, otra intervención de la recopiladoranarradora "precediendo" propiamente la "narración". En este sentido, cabe apuntar que la escritora prepara un escenario, no para los protagonistas/personajes, sino para la literatura, pues ya que esta no cabe en una geocultura desconocida, por lo que hay que abrirle espacio, y de cierto modo imponerla, pues "colonizar" es la acción más propia de este ejercicio.

Este hecho acerca de la forma establece una estrategia particular de lectura, regida por una voz de autoridad, la Antropología, desde donde la narradora despliega una intermediación de carácter literario de tal suerte que ambos espacios enmarcan la "oralidad" traducida en narración literaria, convocando así solo al lector occidentalizado, convocatoria propia del sistema de comunicación culto que se legitima desde una metrópoli.

En el otro espacio textual de La creación de La Tierra y otras Historias del buen Sibú y de los bribris está su referente, un mundo desconocido que se presenta como realidad incontrastable, propuesto como deslumbrante, ante el cual la narradora se confiesa fiel admiradora y por ello debe representarlo en términos de verdad, pero al mismo tiempo debe someterlo a determinado tratamiento para hacerlo legible a una óptica que le es extraña, comenzando por la de la misma narradora, siendo esta la forma de presentación del texto.

En un nivel de mayor complejidad, la autora apela a su repertorio cultural, confesión expuesta en la sección prologal del texto: "Estas historias... están inspiradas en la obra de investigación realizada por la antropóloga costarricense...” (p. 7). Esto hace que la particularidad del referente quede velada por la intromisión de otras formas de realidad, entre ellas el uso de una lengua y su particular expresión académica.

Con base en este análisis de carácter comprehensivo de algunos ejemplares de la literatura costarricense, se puede concluir que las representaciones del indígena propuestas perfilan un imaginario social y cultural heterogéneo en tanto se considere la plurivocidad particular de cada formación social incorporada y de la superposición de temporalidades que la componen. Se trata sobre cómo funciona el tiempo en un lugar cultural particular, y por ello es fundamental que todo texto sea leído asumiendo en él lo social, y esto en la historia, la que se convierte en eje explicativo e interpretativo de nuestra literatura.

Finalmente, visualizar en La creación de La Tierra y otras Historias del Buen Sibú y de los Bribris la acción de las fuerzas culturales no es difícil, puesto que ya por la misma forma se puede establecer, y también es posible observar los intereses políticos en virtud de la militancia política de Ferreto. En el fondo, el texto de marras se limita a reproducir en términos específicos una cosmovisión conquistada y dominada, y con ello, indicar la aparición de lo que Mariátegui llamó literaturas no orgánicas nacionales. 


\section{Referencias bibliográficas}

Bozzoli, M. (1979). El nacimiento y la muerte entre los Bribris. San José: EUCR.

Cornejo, A. (1978). El indigenismo y las literaturas heterogéneas. Su doble estatuto sociocultural. Revista de Crítica literaria Latinoamericana. $\mathrm{N}^{\mathrm{O}}$ 7. Págs: $67-85$.

Cros, E. (2003). El sujeto cultural, sociocrítica y psicoanálisis. Medellín: Fondo Editorial Universidad.

Ferreto, A. (1985). La creación de la Tierra y otras Historias del buen Sibú y de los bribris. San José: UNED.

Genette, G. (1987). Palimpsestos. Literatura en segundo grado. Tr. Celia Fernández P. Taurus. Bs As.

Marcone, J. (1997). La oralidad escrita. Sobre reivindicación y reinscripción del discurso oral. Pontificia Universidad Católica. Perú.

Mato, D. (1995). El arte de narrar y la noción de literatura oral. Protopanorama intercultural y problemas epistemológicos. Universidad Central de Venezuela. Caracas.

Rama, Á. (1974). Sistema literario y sistema social en Hispanoamérica. Varios. Literatura y Praxis en América Latina. Págs: 81-107. Monte Ávila. Caracas.

Zavala, M. (1998). La literatura indígena centroamericana ayer y hoy. Kipus. Revista andina de letras. UASB.

\section{Bibliografía}

Alberola, H. C. (2011). La traducción de la oralidad en los textos dramáticos: el caso de Cat on a Hot Tin Roof. Fòrum de Recerca, (16), 605-613.

Bozzoli, M. (1982). Narraciones talamanqueñas. Revista Vínculos. Vol 8 No $^{0}$ 1-2. Págs 1-12. Museo Nacional de Costa Rica.

Cantillano Vives, O. (2006). El pozo encantado, Los cuentos de mi tía Panchita.. San José: EUNED.

Chacón, A. (1997). La jurisdicción de los paratextos en los libros que reescriben la oralidad. Káñina. Revista de Artes y Letras de la Universidad de Costa Rica. Vol XXI. No especial (2) Págs: 91-96.

Constenla U, A. (1996). Poesía tradicional indígena costarricense. San José: EUCR.

Cornejo-Polar, A. (1998). "Apéndice”. Mestizaje, Transculturación, Heterogeneidad. Revista de Crítica literaria Latinoamericana. $\mathrm{N}^{\circ}$ 47. Págs: $54^{-56 .}$

Cornejo-Polar, A. (1998). Mestizaje e Hibridez: Los riesgos de las metáforas. Revista de Critica literaria Latinoamericana. $\mathrm{N}^{\circ}$ 47. Págs: 7-11.

Dorra, R. (1997). “¿Grafocentrismo o fonocentrismo”. Perspectivas para un estudio de la oralidad". Memorias. Jornadas Andinas de Literatura Latinoamericana. Ed. Ricardo J. Kaliman. Vol. I. Tucumán: Univ. Nacional de Tucumán. 56-73.

Fernández Sandí, H. (1987). Cosmogonía, biocosmogonía y antropogonía en La creación de la Tierra y otras Historias del buen Sibú y de los bribris de Adela Ferreto. Káñina, vol XI, nº 2 . Págs: 65-71. Revista de la Universidad de Costa Rica. San José. 
Ostria-González, M. (1997). Ficcionalización de las lenguas amerindias en el discurso literario hispanoamericano. Memoria de JALLA Tucuman 1995. Argentina.

Ostria-González, M. (2001). Literatura oral, oralidad ficticia. Estudios Filológicos, (36), 71-80.

O’Gorman, E. (1958). La invención de América. El universalismo de la cultura de Occidente. Fondo de cultura económica. México

Pandolfi, M. y Ureña, L. (200o). Tesis para optar por el grado de Licenciatura en Filología española. La identidad cultural en textos de tradición de oral. Universidad de Costa Rica.

Toro Henao, D. (2012). Estética de la palabra viva. Las tradiciones orales como creaciones literarias. Universidad de Antioquia. Colombia. 